\title{
What leads to the expectation to return to work? Insights from a Theory of Planned Behavior (TPB) model of future work outcomes
}

\author{
Debra A. Dunstan ${ }^{\mathrm{a}, *}$, Tanya Covic ${ }^{\mathrm{b}}$ and Graham A. Tyson ${ }^{\mathrm{c}}$ \\ ${ }^{a}$ Discipline of Psychology, School of Behavioural, Cognitive and Social Sciences, University of New England, \\ Armidale, Australia \\ ${ }^{\mathrm{b}}$ School of Psychology, University of Western Sydney, Sydney, Australia \\ ${ }^{\mathrm{c}}$ School of Psychology, Charles Sturt University, Bathurst, Australia
}

Received 8 November 2011

Accepted 7 August 2012

\begin{abstract}
.
OBJECTIVE: This study used a Theory of Planned Behavior (TPB) model to identify the factors influencing the future work expectations and outcomes of employees with a musculoskeletal injury.

PARTICIPANTS: Australians with a compensable work injury $(N=174)$, mean age $=43.7$ years, $53.2 \%$ male, $48.3 \%$ back injury, and $34.2 \%$ unskilled.

METHODS: A TPB model of the target behavior 'working, or continuing to work ... three months from now' was constructed. A questionnaire measuring the model's components was completed at baseline and three-months follow-up.

RESULTS: The model met standard psychometric requirements. Attitude, Subjective Norm and Perceived Behavioral Control explained $76 \%$ of the variance in Behavioral Intention $\left(R^{2}=0.76, p<0.001\right)$. Behavioral Intention (the expectation to return to work) explained $51 \%$ of the variance in work participation at follow-up (Nagelkerke $R^{2}=0.51, p<0.001$; sensitivity $=86.4 \%$, specificity $=71.2 \%$ ). The strength of key influences on expectations varied according to employment status, but included the availability of modified duties, social aspects of work, the opinion of the treating doctor, co-worker support, pain, and functional limitations.
\end{abstract}

CONCLUSION: The TPG is a useful model and conceptual framework for integrating the biopsychosocial determinants of return to work (RTW) and identifying the influences on future work expectations and outcomes.

Keywords: Work disability, modified work, co-worker support

\section{Introduction}

Musculoskeletal injury is the most prevalent workplace injury and the main cause of work disability and sickness absence in Australia [1,2] and other industrial-

* Address for correspondence: Debra A. Dunstan, Discipline of Psychology, School of Behavioural, Cognitive and Social Sciences, University of New England, Armidale 2351, Australia. Tel.: +61 2 6773 3764; Fax: +61 26773 3820; E-mail: ddunstan@une.edu.au. ized nations [3]. In about $10 \%$ of cases, the person with an injury does not resume employment and this leads to substantial socioeconomic costs $[4,5]$. Facilitating the return to work (RTW) outcomes of employees on long-term sickness absence remains a challenge [6] and is subject to continuing investigation [7], and analysis, using theoretical models to conceptualize the relationships between influencing factors and processes [8]. What is known, is that the most consistent and powerful predictor of RTW is the employee with an injury's ex- 


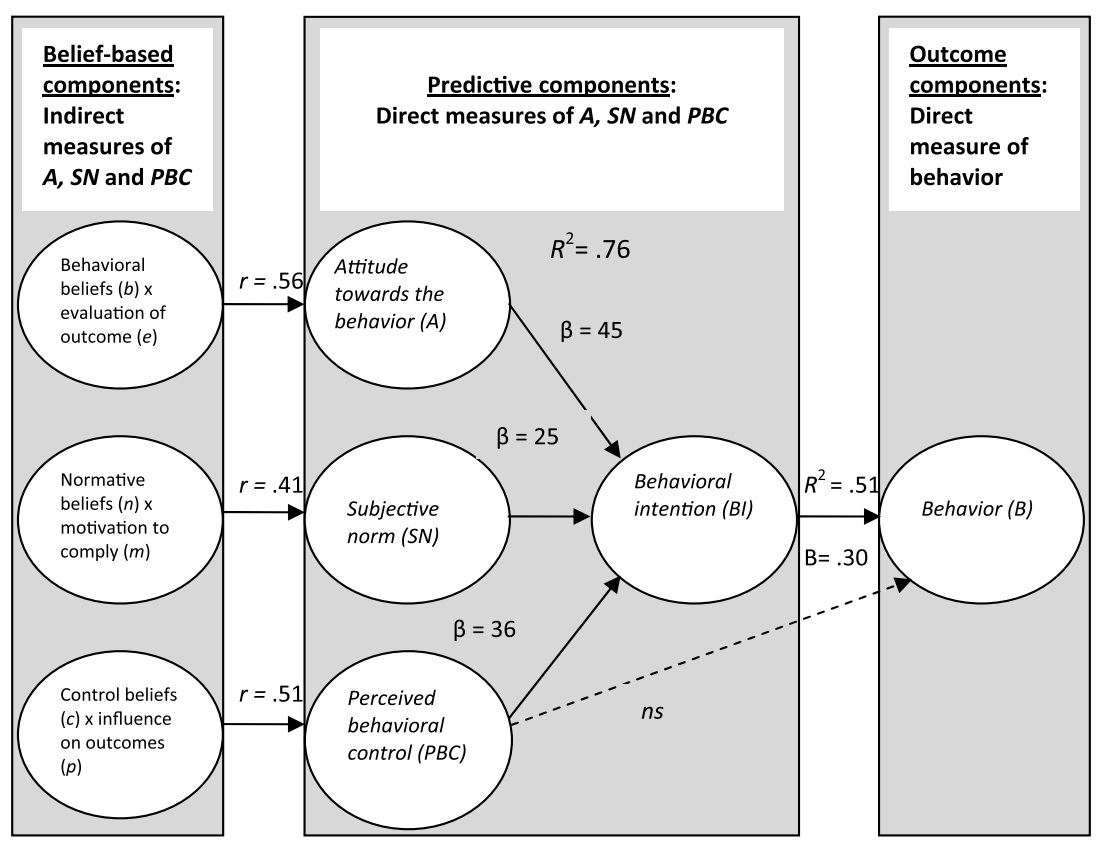

Fig. 1. The Theory of Planned Behavior (TPB) Model and the relationships between the components found in this study.

pectation to do so [9-13]. Therefore, if it were possible to pinpoint the issues leading to this expectation, then the keys to more effective intervention might become evident. To this end, Ajzen's Theory of Planned Behavior (TPB) [14], a social cognitive model of the influences on an individual's decision to engage in a particular behavior [15], has been identified as a promising framework [16] for detecting the known physical, psychological and social determinants of RTW [6,17-20] most strongly impacting expectations.

The main premise of the TPB (illustrated in Fig. 1) is that a person's Behavioral Intention $(B I)$, which can be conceptualized as motivation or expectation [15], is the most proximal and strongest determinant of behavioral performance. According to the TPB, $B I$ is a function of Attitudes (A), Subjective Norm (SN) and Perceived Behavioral Control $(P B C)$. Attitudes are appraisals of the behavior determined by beliefs about the consequences of performing the behavior $(b)$ and an evaluation of the importance of these consequences $(e)$. Subjective Norm is the perceived social pressure to perform the behavior, derived from beliefs about what important others think $(n)$ and the motivation to comply with these opinions $(m)$. Perceived Behavioral Control is the ease or difficulty of engaging in the behavior, determined by beliefs about personal resources, knowledge, skills and opportunities $(c)$ and the power of these elements to influence behavioral outcomes $(p)$.
In summary, the TPB proposes that a person will intend to engage in a behavior if they have an overall favorable attitude towards it, believe that significant others desire such action, and possess the necessary resources and opportunities for its execution [21]. However, if the first two conditions exist, but the person has perceived limited ability or significant barriers to achievement, then the behavior may not be performed. Indeed, in circumstances of limited control, $P B C$ will have an increasingly direct influence on Behavioral $(B)$ as true limitations increase [21].

In considering the usefulness of the TPB for understanding the factors influencing the expectation of future work participation, two strengths emerge: first, the model embraces the key role of expectations in determining performance $[12,13]$; and second, it accommodates for influences that are beyond the individual's immediate control (which in the case of work disability can include job loss, lack of transferable skills, and the like) [22]. By identifying the component(s) significantly related to the intention or expectation to perform the behavior (i.e., $B I$ ), then inspecting the means of the underlying belief items, it becomes evident which issues are influencing expectations [23]. Prior to this study, however, the TPB had only been used conceptually [16], and not applied with fidelity (through the construction of a behavior-specific measurement questionnaire) to identify the particular influences on RTW expectations in the presence of work disability. 
While a TPB questionnaire can be used to predict behavioral outcomes, the focus of this study was not the development of a tool to predict RTW; instead, we sought to apply the TBP to gain knowledge about the relative influence of the multifactorial determinants of work transitions and outcomes - those lying within and outside of the person [22] - on RTW expectations. By adhering strictly to standard procedures established by the model's authors [14,21,24,25], our aim was to develop, validate and analyze a TPB model of the factors influencing the future work expectations and outcomes of employees chronically work-disabled by a musculoskeletal condition.

\section{Methodology}

The Charles Sturt University Human Ethics in Research Committee approved this study. The methodology followed the step-by-step procedures set out by the author of the Theory of Planned Behavior [21,24, 26] and are described in detail below. Table 1 displays the procedural stages, steps and parties involved in developing a TPB model of a specific behavior and lists the order in which they were performed in this study. In brief, Stage 1 involves the development of scales to measure the components of the model. A key aspect of this stage is the use of a pilot group drawn from the relevant population [24]. Stage 2 involves the psychometric evaluation of the scales and validation of the model. Once validated, the scales are combined into a questionnaire which is completed by a sample of the target population. Stage 3 involves examination and analysis of the sample's scores on the developed TBP questionnaire to identify the strongest determinants of future work expectations.

\subsection{Stage 1: Development of the TPB component scales and model}

\subsubsection{Participants}

We recruited a developmental sample $(n=19)$ by convenience sampling. This consisted of the three researchers - all psychologists - and 16 employees (disabled by a musculoskeletal injury) who had consulted the first author (DD; a clinical psychologist) in the 12 months preceding this study. This sample, which was similar in size to those used in TPB studies of rehabilitation behaviors [27], ranged in age from 26 to 56 years $(M=43.6, S D=8.8)$, eight were male and eight were female, $87 \%$ were partnered; $18 \%$ had
Year 12 education; the mean sickness absence was 10.9 months $(S D=8.4$, range $=2.0$ to 51.9$), 11$ had back injuries, the mean pain severity $(0-10)$ was 6.7 $(S D=1.8)$, nine were unskilled workers, eight were 'off work/sickness absent' and eight were 'at work' performing modified duties. Among the sample, the researchers defined the behavior, DD and all injured employees participated in item generation, the researchers conducted an expert review of items, and the whole sample contributed to a final review.

\subsubsection{Procedure}

Step 1: This involved defining the goal behavior in terms of a target, action, context and timing. Thus, RTW was defined as 'working, or continuing to work (behavior), in some paid (context) employment (target) three months from now (time)'. As several studies [28-30] of pain-disabled injured workers have documented this population's regular movement in and out of the workforce, or between full-time and parttime employment, it was important to accommodate for this phenomenon and include participants 'at work', but still disabled to some degree, as well as those 'off work/sickness absent' due to ongoing disability.

Step 2: The basic wording was applied to all TPB components to ensure compatibility between each scale, and, to maximize the relationship between the components and the predicted behavior [21].

Step 3: This step involved the generation of items for the indirect (belief-based) and direct measures of the model's constructs (see Table 2). Behavioral beliefs (b), which theoretically underlie $A$, were elicited by (i) asking the injured employees to list the advantages and disadvantages of working, and (ii) from the researcher's opinions informed by the relevant literature. Normative Beliefs ( $n$; those that underlie $S N$ ) were elicited by asking the injured employees to identify the individuals or groups (i.e., the referents) who would have an opinion about them working despite ongoing work disability. Control beliefs ( $c$; which underlie $P B C$ ) were generated by asking the employees to list the factors that would make working, or continuing to work, easy or difficult to do.

Step 4: From 13 potential behavioural beliefs items, eight were retained in accordance with Ajzen's (the model's author) ' $75 \%$ rule' (i.e., the retained items accounted for $75 \%$ of the cumulative frequency of all items) [26, p. 71]. The rejected items were: 'less time with family', 'travel costs', 'can't do what I want to', 'be active' and 'have status.' From a list of eight possible referents, six were retained in accordance with the 
Table 1

Stages and steps in the development and validation of a TPB behavior specific model and scales

Stage 1: Development of the TPB component scales and model

\begin{tabular}{|c|c|c|}
\hline & Steps & Parties involved \\
\hline 1. & Define the behavior $(B)$ in terms of context, target and time. & Researchers \\
\hline 2. & $\begin{array}{l}\text { Apply this wording to each TPB component (i.e. Behavioral in- } \\
\text { tention }[B I] \text {, Attitude }[A] \text {, Subjective Norm }[S N] \text { and Perceived } \\
\text { Behavioral Control }[P B C] \text { ). }\end{array}$ & Researchers \\
\hline 3. & Identify the salient population beliefs underlying each component & $\begin{array}{l}\text { A pilot group representative of the population generates the be- } \\
\text { liefs. The researchers short-list the beliefs for each component } \\
\text { to those that account for } 75 \% \text { of the cumulative frequency of } \\
\text { all items. }\end{array}$ \\
\hline 4. & $\begin{array}{l}\text { From the above results, construct the indirect measure scale items } \\
\text { for } A, S N \text { and } P B C\end{array}$ & Researchers \\
\hline 5. & $\begin{array}{l}\text { Using standard wordings, construct potential direct measures scales } \\
\text { items of each component }(B I, A, S N \text { and } P B C)\end{array}$ & Researchers \\
\hline 6. & Short-list the above to $4-6$ items & Consensus between the researchers and the pilot group \\
\hline 7. & Construct the questionnaire and preliminary TPB model & Researchers expert review \\
\hline
\end{tabular}

Stage 2: Psychometric analysis of the TPB component scales and model validation

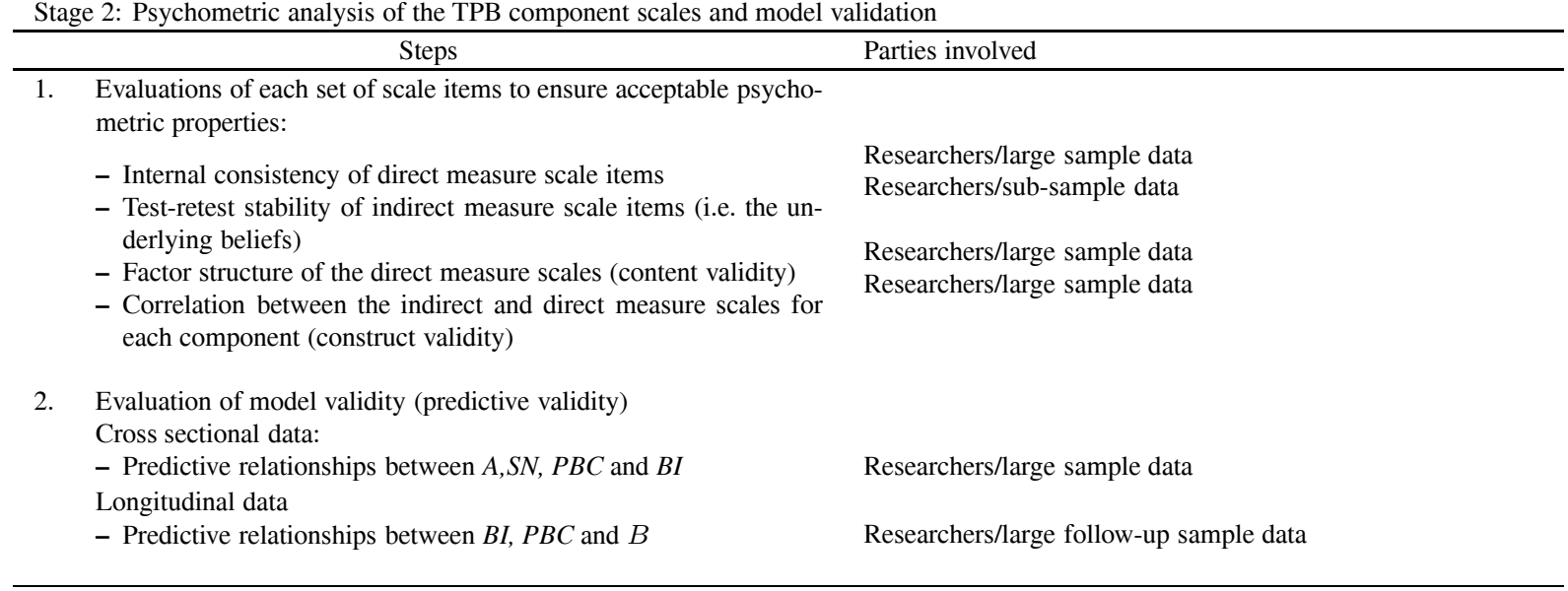

'75\% rule'. Rejected potential referents were: 'rehabilitation provider' and 'partner'. Finally, from 16 potential facilitators or inhibitors of working, nine were retained using the ' $75 \%$ rule'. Rejected potential items were: age, sex, education, ethnicity and general health. Scale items eliciting the strength rating for each group of beliefs (i.e., $e, m$, and $p$ ) were also developed according to standard procedures.

Step 5: Items for the direct measures of Behavioral Intention (BI), Attitude (A), Subjective Norm (SN) and Perceived Behavioral Control $(P B C)$ were generated and were selected on the basis of group consensus. For the direct measure of $B I$, four items canvassing 'plans, desires and self-prediction concerning the performance of the behavior' [31, p. 134] namely, future work participation, were chosen. Another four items, with bipolar adjectives as end-points, were chosen to measure $A$ (i.e., the 'perceived instrumentality' and anticipated 'experiential or affective qualities' [21, p. 5], of working). Three items were chosen for the direct measure of
$S N$ : two items to canvass the theoretical injunctive subcomponent (i.e., the belief that important others would want you to perform the behavior) and one item to assess the descriptive subcomponent (whether important others will themselves be performing the behavior) [21, p. 6]. Finally, four items were chosen for the direct measure of $P B C$; two items to canvas the hypothesized subcomponent of 'confidence to perform the behavior' and another two to measure the 'controllability of the behavior' [21, p. 7].

Steps 6 and 7: The last steps of the developmental process involved confirming that the wording of each item was appropriate for the population of interest and randomly assembling the 23 items into a combined questionnaire.

\subsection{Stage 2: Psychometric evaluation of the TPB component scales and model validation}

Ajzen's recommended procedures for evaluating TBP component scales, and the associated model, were 
Table 2

The wording of items in the TPB predictive model of RTW expectations and outcomes in employees with a musculoskeletal injury

\begin{tabular}{|c|c|}
\hline Direct measure scales & End-point descriptors \\
\hline \multicolumn{2}{|l|}{ Behavioral Intervention $(\mathrm{BI})(\propto=0.91)$} \\
\hline The chance of me ... & Very low/Very high \\
\hline I want to be .... & Strongly disagree/Strongly agree \\
\hline I expect to be .... & Strongly disagree/Strongly agree \\
\hline I plan to be .... & Strongly disagree/Strongly agree \\
\hline \multicolumn{2}{|l|}{ Attitude (A) $(\propto=0.93)$} \\
\hline \multicolumn{2}{|l|}{ Instrumental items } \\
\hline Good - Bad & (Item) \\
\hline Foolish - Wise & (Item) \\
\hline Harmful - Beneficial & (Item) \\
\hline \multicolumn{2}{|l|}{ Experiential item } \\
\hline Scary - Enjoyable & (Item) \\
\hline \multicolumn{2}{|l|}{ Subjective Norm $(\mathrm{SN})(\propto=0.94)$} \\
\hline \multicolumn{2}{|l|}{ Injunctive items } \\
\hline Most people who are important to me think I should be ... & Not at all true/Very true \\
\hline Most people who are important to me want me to be ... & Not at all true/Very true \\
\hline \multicolumn{2}{|l|}{ Perceived Behavioral Control (PBC) $(\propto=0.86)$} \\
\hline \multicolumn{2}{|l|}{ Confidence/Self-efficacy items } \\
\hline I am confident in my ability to be ... & Strongly disagree/Strongly agree \\
\hline I will have no difficulty ... & Strongly disagree/Strongly agree \\
\hline \multicolumn{2}{|l|}{ Controllability/Outcome Expectancy items } \\
\hline Whether I am . . . is entirely up to me & Strongly disagree/Strongly agree \\
\hline$\ldots$ is under my control & Strongly disagree/Strongly agree \\
\hline \multicolumn{2}{|l|}{ Indirect measure scales } \\
\hline \multicolumn{2}{|l|}{$\begin{array}{l}\text { Behavioral Beliefs (test-retest stability: } r=0.57 \text { ) } \\
\text { Advantages of the working }\end{array}$} \\
\hline Increase my income & Not a-all/Very much \\
\hline Help me feel useful and/or productive & Not at all/Very much \\
\hline Give me respect and acceptance by people & Not at all/Very much \\
\hline Increase my social contact with people & Not at all/Very much \\
\hline \multicolumn{2}{|l|}{ Disadvantages of working } \\
\hline Increase my pain & Not at all/Very much \\
\hline Make my condition worse & Not at all/Very much \\
\hline Prohibit me from resting when I want to & Not at all/Very much \\
\hline Cause me to feel stressed & Not at all/Very much \\
\hline \multicolumn{2}{|l|}{ Normative beliefs (test re-rest stability: $r=0.89$ ) } \\
\hline \multicolumn{2}{|l|}{ Significant referents } \\
\hline Close family member (e.g. spouse, parent, brother) & Not at all true/Very true \\
\hline Doctor & Not at all true/Very true \\
\hline Friends & Not at all true/Very true \\
\hline Pre-injury employer & Not at all true/Very true \\
\hline Pre-injury co-workers & Not at all true/Very true \\
\hline Insurance company & Not at all true/Very true \\
\hline \multicolumn{2}{|l|}{ Control beliefs (test re-test stability: $r=0.87$ ) } \\
\hline \multicolumn{2}{|l|}{ Facilitators of working } \\
\hline Having duties to go to & Not at all/Very much \\
\hline Feeling confident & Not at all/Very much \\
\hline Receiving a positive attitude from an employer & Not at all/Very much \\
\hline Support and/or co-operation from co workers & Not at all/Very much \\
\hline \multicolumn{2}{|l|}{ Inhibitors of working } \\
\hline Being in pain & Not at all/Very much \\
\hline Needing medical tests, examinations or procedures & Not at all/Very much \\
\hline Having restricted physical capacity & Not at all/Very much \\
\hline Being on Workers' Compensation & Not at all/Very much \\
\hline Feeling down or depressed & Not at all/Very much \\
\hline
\end{tabular}

${ }^{*} \mathrm{RTW}=$ return to work. 
Table 3

Demographic and biographic features of the total sample $(N=158)$ and follow-up subsample (at work: $n=69$; off work/sickness absent: $n=$ 62) of employees with a musculoskeletal injury

\begin{tabular}{|c|c|c|c|c|c|}
\hline \multirow[t]{2}{*}{ Variable } & \multirow[b]{2}{*}{$\begin{array}{l}\text { Total sample } \\
(N=158)\end{array}$} & \multicolumn{4}{|c|}{ Follow-up subsample } \\
\hline & & $\begin{array}{l}\text { At work } \\
(n=69)\end{array}$ & $\begin{array}{l}\text { Off work sickness } \\
\text { absent }(n=62)\end{array}$ & $\begin{array}{l}\text { Difference } \\
\text { measure }\end{array}$ & $\begin{array}{c}\text { Significance and magnitude } \\
\text { of difference }\end{array}$ \\
\hline \multicolumn{6}{|l|}{ Age in years: } \\
\hline Mean $(S D)$ & $43.76(11.49)$ & $43.86(11.26)$ & $44.26(11.88)$ & $t(128)=0.198$ & $p=0.843, n s$ \\
\hline Range & 18.0-66.1 & & & & \\
\hline \multicolumn{6}{|l|}{ Gender: } \\
\hline Male $n(\%)$ & $84(53.2)$ & $34(49.3)$ & $37(52.1)$ & $\chi^{2}(1)=1.42$ & $p=0.233, n s$ \\
\hline \multicolumn{6}{|l|}{ Marital status: } \\
\hline Partnered $n(\%)$ & $93(58.9)$ & $44(63.8)$ & $38(61.3)$ & $\chi^{2}(2)=1.37$ & $p=0.504, n s$ \\
\hline \multicolumn{6}{|l|}{${ }^{*}$ Education: } \\
\hline$<$ Year $10 n(\%)$ & $35(22.2)$ & $9(13.2)$ & $18(29.5)$ & $\chi^{2}(5)=9.36$ & $p=0.095, n s$ \\
\hline Year 10 & $39(24.7)$ & & & & \\
\hline Year 12 & $21(13.3)$ & & & & \\
\hline \multicolumn{6}{|l|}{ Time since injury (in months): } \\
\hline Mean $(S D)$ & $33.77(34.13)$ & $30.57(26.95)$ & $41.41(42.79)$ & $t(127)=1.73$ & $p=0.085, n s$ \\
\hline Range & $2.7-247.0$ & & & & \\
\hline \multicolumn{6}{|l|}{$\begin{array}{l}\text { Duration of total sickness absence } \\
\text { (in months, Time 1): }\end{array}$} \\
\hline Mean $(S D)$ & $9.92(17.13)$ & $2.19(10.71)$ & 20.69 (19.74) & $t(5.72)=4.45$ & $p<0.001$ \\
\hline Range & $0.0-111.5$ & & & & $d=-1.16$ \\
\hline \multicolumn{6}{|l|}{ * Site of injury: } \\
\hline Back $n(\%)$ & $76(48.1)$ & $33(47.8)$ & $32(51.6)$ & $\chi^{2}(4)=6.70$ & $p=0.153, n s$ \\
\hline Upper limb & $26(16.5)$ & & & & \\
\hline Other & $23(14.6)$ & & & & \\
\hline \multicolumn{6}{|l|}{ Pain severity $(0-10)$ : } \\
\hline Mean $(S D)$ & $5.86(2.60)$ & $5.07(2.79)$ & $6.90(1.71)$ & $t(129)=4.45$ & $p<0.001$ \\
\hline Range & $0.0-10.0$ & & & & $d=-0.79$ \\
\hline \multicolumn{6}{|l|}{ Previous injury: } \\
\hline Nil $n(\%)$ & $140(88.6)$ & $8(11.6)$ & $9(14.5)$ & $\chi^{2}(1)=0.005$ & $p=0.944, n s$ \\
\hline \multicolumn{6}{|l|}{ *Occupation: $n(\%)$} \\
\hline Unskilled workers & $54(34.2)$ & $18(26.1)$ & $29(46.8)$ & $\chi^{2}(4)=6.70$ & $p=0.153, n s$ \\
\hline Skilled workers & $36(12.7)$ & & & & \\
\hline Professionals & $23(14.6)$ & & & & \\
\hline \multicolumn{6}{|l|}{ Modified duties: } \\
\hline Yes $n(\%)$ & $89(56.3)$ & $59(85.5)$ & $12(19.4)$ & $\chi^{2}(1)=56.73$ & $p<0.001$ \\
\hline \multicolumn{6}{|l|}{ Employment status: } \\
\hline Off work/sickness absent $n(\%)$ & $76(48.1)$ & & $62(47.32)$ & Binomial & $p=0.191, n s$ \\
\hline
\end{tabular}

${ }^{*}$ Most highly rated of five categories: Education: < Year 10, Year 10, Year 12, Technical College, University.

Site of Injury: back, neck, upper limb, lower limb, other.

Occupation: professional, managers/administrators, skilled, semi-skilled, unskilled.

followed [21]. According to these procedures, scale reliability is assessed by determining the internal consistency (Cronbach's alpha coefficient) of the direct measure scales and the test-retest stability of the indirect measure scales. Scale validity is shown if (a) the factor structure of the direct measure scales meets theoretical requirements (content validity) and (b) the indirect and direct measure scales are positively correlated (construct validity). The model is validated if the predictive relationships between the components are significant. These analyses are reported in the Results section.

\subsubsection{Participants}

A total of 158 work-disabled employees (see Table 3 for demographic and biographic details) formed the validation sample and completed the TPB measurement scales once. The sample's features indicate that it was representative of the population of Australian injured workers in terms of average age, gender mix, site of musculoskeletal injury and occupation [32]. To gain data for a test-retest stability analysis, a subsample of 16 conveniently selected participants completed the scales a second time, one week after the first. A further subsample $(n=131)$ provided three-month follow-up data: 69 of these participants were 'at work' and 62 were 'off work/sickness absent' (see Table 3 for full details). There were no differences between the subgroups in terms of age, gender, marital status, level of education, time since injury, percent with back 
injuries, history of previous injury, or occupation, but the 'off work/sickness absent' group had significantly longer sickness absence and greater pain severity, and were less likely to have been offered modified duties.

\subsubsection{Measures}

The following three measures were used to identify the features of the sample and to evaluate the validity of the TPB model of future work expectations and outcomes.

The Background Information Questionnaire was used to obtain participants' demographic and biographic details, which are summarized in Table 3.

The TPB Future Work Expectations Questionnaire (developed in the preceding stage of this study) consists of 23 items distributed across seven subscales that measure the components of a TPB model of the influences on 'working, or continuing to work, in some paid employment three months from now'. All items are rated on a seven-point bipolar scale $(-3$ to +3$)$, except belief strength which is rated on a unipolar scale (1-7); the end-point descriptors being specific to the questions. Each predictive component $(A, S N, P C B$ and $B I)$ has a direct measure scale - the sum of each scale's items forming that scale's score. $A, S N$ and $P B C$ also have an indirect, belief-based measure - the total score of each scale being the sum of the multiplicative composites of the ratings given to individual belief items and the corresponding outcome evaluation (i.e., $A=\Sigma b e, S N$ $=\Sigma n m, P B C=\Sigma c p$ ). (Full scoring details may be obtained from the correspondence author).

The Three Month Follow-up Telephone Interview asked participants to categorize their current employment status as follows: at work/pre-injury duties; at work/modified duties; or, off work/sickness absent.

\subsubsection{Procedure}

Participants in the validation sample were recruited by staff from a number of metropolitan and rural occupational rehabilitation agencies who identified clients meeting the following criteria: (a) compensable workrelated musculoskeletal injury causing work disability; (b) attained the age of 18 years; and, (c) able to read and speak English. Suitable people were provided with a package containing a written information statement (including advice that a three-month follow-up of employment status was desired), a questionnaire booklet, a reply paid envelope addressed to the first author; and, an offer to receive a $\$ 10$ gift voucher in appreciation for participation. (Those who wished to receive the voucher ticked an appropriate box). A total of 450 question- naire packages were dispensed across nine agencies; the response rate was $35 \%$. To collect longitudinal data, a self-report of work participation status was obtained from participants who had consented and could be contacted by telephone.

\section{Results}

This section reports on the analysis of data collected in Stage 2 (evaluation of the psychometric properties of the TBP component scales and validation of the TPB model of future work expectations and outcomes); and, Stage 3 (examination and analysis of scores on the TBP model questionnaire) to identify the determinants of future work expectations. Results are reported in the procedural sequence listed in Table 1.

\subsection{Stage 2: Step 1 - evaluation of the psychometric properties of the TPB component scales}

\subsubsection{Reliability}

Direct measure scales - internal consistency. The $B I$ scale, consisting of four items, demonstrated good internal consistency $(\alpha=0.91)$. Similar good results were found for the four-item $A$ scale ( $\alpha=0.93$ ) and the four-item $P B C$ scale $(\alpha=0.86)$. Unsatisfactory internal consistency was found for the three-item $S N$ scale $(\alpha=0.65)$ but, after removing one item showing low correlation with the total scale score $(r=0.04)$, good internal consistency ( $\alpha=0.94)$ was achieved.

Indirect measure scales - test re-test stability. The Pearson Product Moment correlations between the total scores of the indirect measure scales for $A, S N$ and $P B C$ - completed twice by $n=16$ participants - were large, indicating that the scales had good temporal stability: behavioral beliefs $(r=0.57, n=16, p<0.05$, two-tailed); normative beliefs ( $r=0.89, n=16, p<$ 0.01 , two-tailed) and control beliefs ( $r=0.87, n=16$, $p<0.01$, two-tailed).

\subsubsection{Validity}

The content validity of the indirect measure scales was assessed by exploring the factor structure, analyzed by means of Principle Components Analysis with Varimax Rotation and Kaiser Normalization. Components with an Eigenvalue of greater than one were extracted [33] and no items required removal. Analysis of the behavioral belief items (underlying $A$ ) yielded a two-component solution, which is consistent with the TPB theoretical requirements. The components named 
Table 4

Principle components analysis loadings for the indirect measures of $\mathrm{A}, \mathrm{SN}$ and $\mathrm{PBC}(N=158)$

\begin{tabular}{|c|c|c|}
\hline \multirow{2}{*}{$\begin{array}{l}\text { Attitude } \\
\text { Behavioral beliefs by expected component }\end{array}$} & \multicolumn{2}{|c|}{ Component loadings } \\
\hline & Disadvantages of working & Advantages of working \\
\hline \multicolumn{3}{|l|}{ Advantages of working } \\
\hline Gain respect and acceptance & & 0.84 \\
\hline Increased social contact & & 0.85 \\
\hline Feel useful and productive & -0.18 & 0.74 \\
\hline Increased income & 0.15 & 0.47 \\
\hline \multicolumn{3}{|l|}{ Disadvantages of working } \\
\hline Increased pain & 0.85 & 0.17 \\
\hline Make condition worse & 0.85 & \\
\hline Prohibit resting & 0.74 & -0.10 \\
\hline Cause stress & 0.55 & -0.23 \\
\hline Explained variance $(\%)$ & 29.52 & 28.73 \\
\hline Subjective norm & \multicolumn{2}{|c|}{ Component loadings } \\
\hline Normative beliefs & \multicolumn{2}{|c|}{ Referents with an opinion about working } \\
\hline Co-workers & \multicolumn{2}{|c|}{0.80} \\
\hline Friends & \multicolumn{2}{|l|}{0.80} \\
\hline Doctor & \multicolumn{2}{|l|}{0.79} \\
\hline Closest family member & \multicolumn{2}{|l|}{0.77} \\
\hline Pre-injury employer & \multicolumn{2}{|l|}{0.77} \\
\hline Insurer & \multicolumn{2}{|l|}{$\mathbf{0 . 5 0}$} \\
\hline Explained variance $(\%)$ & \multicolumn{2}{|l|}{56.05} \\
\hline Perceived behavioral control & \multicolumn{2}{|c|}{ Component loadings } \\
\hline Control beliefs by expected component & Facilitators of working & Inhibitors of working \\
\hline \multicolumn{3}{|l|}{ Facilitators of working } \\
\hline Co-worker support & 0.87 & \\
\hline Employer support & 0.86 & \\
\hline Having duties to go to & 0.75 & -0.32 \\
\hline Confidence to do the job & 0.75 & -0.31 \\
\hline Feeling down or depressed & -0.52 & 0.39 \\
\hline \multicolumn{3}{|l|}{ Inhibitors of working } \\
\hline Restricted physical capacity & -0.19 & 0.84 \\
\hline Being in pain & -0.21 & 0.80 \\
\hline Being on Workers' Compensation & 0.19 & 0.74 \\
\hline Needing medical tests/examinations & & 0.66 \\
\hline Explained variance $(\%)$ & 33.76 & 29.82 \\
\hline
\end{tabular}

'Advantages of working' and 'Disadvantages of working' explained $29.52 \%$ and $28.73 \%$ of the variance in $A$. Results from analysis of the normative belief items (underlying $S N$ ) met the theoretical requirement that all items load onto one normative beliefs component, which accounted for $56.05 \%$ of the explained variance in $S N$. Analysis of the control belief items (underlying $P B C$ ) yielded a two-component solution, which was consistent with the TPB requirement that control beliefs should represent factors that either facilitate or inhibit behavioral performance. These components, named 'Facilitators of working' and 'Inhibitors of working', explained $33.76 \%$ and $29.82 \%$ of the variance in $P B C$. The indirect measure scales' component structure and item loadings are shown in Table 4.

The construct validity of the indirect and direct measure scales was evaluated by examining the correlation between these measures of $A, S N$ and $P B C$. Moder- ate and large correlations [34] were found between the measures of $A(r=0.56, p<0.01), S N(r=0.41, p<$ $0.01)$ and $P B C(r=0.51, p<0.01)$.

\subsection{Stage 2: Step 2 -evaluation of the model's validity}

The validity of a TPB model is demonstrated if a significant predictive relationship is found between the model's components, which are analyzed crosssectionally and longitudinally. Two regressions are necessary: the first involves $A, S N$ and $P B C$ as predictors of the criterion variable $B I$; the second involves $B I$ and $P B C$ as predictors of $B$. All assumptions relating to multiple and logistic regression were met. Although four univariate outliers and one multivariate outlier were detected, examination of the residuals plots did not show any pronounced deviation from lineari- 
ty. Additionally, the Durban-Watson statistics were all within acceptable range $(1.5-2.50)$ for non-sequential dependency.

\subsubsection{Cross sectional data}

A linear multiple regression, using the enter method, was performed to explore the first predictive relationship: that between the direct measure scale scores for $A$, $S N$ and $P B C$, and $B I$ as the dependent variable. A significant model emerged $\left(F_{3,142}=142.013, p=0.001\right)$ explaining $76 \%$ of the variance in the expectation of future work participation $(B I)\left(R^{2}=0.76, \operatorname{Adj} R^{2}=\right.$ $0.74, R=0.87, p<0.001)$. The standardized beta coefficients $(\beta)$ revealed that all three predictor variables explained significant amounts of unique variance in $B I$ (work expectations): $A(\beta=0.45,95 \% \mathrm{CI}$ for $\mathrm{B}[0.33$, $\left.0.57], t=7.56, p<0.001, s r^{2}=0.09\right), S N(\beta=0.25$, $95 \% \mathrm{CI}$ for B [0.25, 0.58], $t=5.18, p<0.00, s r^{2}=$ $0.04)$ and $P B C(\beta=0.36,95 \% \mathrm{CI}$ for $\mathrm{B}[0.45,0.77]$, $\left.t=6.09, p<0.00, s r^{2}=0.05\right)$ (see Fig. 1).

\subsubsection{Longitudinal data}

The second predictive relationship, that between $B I$ and $P B C$, and the criterion variable 'working or, continuing to work, in some paid employment three months from now' $(B)$ - was explored using logistic regression. $B$ was dichotomized into 'at work' and 'off work/sickness absent'. The Omnibus Model Test indicated that the overall fit of the model was significant $\chi^{2}(7)=60.62, \mathrm{df}=2, p<0.001$, suggesting that the predictors reliably distinguished between the work participation outcomes, and accounted for an estimated variance in work participation of $51 \%$ (Nagelkerke $\left.\mathrm{R}^{2}=0.51\right)$. Overall, $79.2 \%$ of predictions were correct; $86.4 \%$ of participants who were 'at work' (sensitivity), and 71.2\% who were 'off work/sickness absent' (specificity) were identified. However, only $B I(\mathrm{~B}=$ 0.30, S.E. $=0.08$, Wald $=14.44, \mathrm{df}=1, p<0.001$ ) significantly predicted future work status suggesting that the behavior was seen to be substantially under volitional control (for $P B C$ : $\mathrm{B}=0.02$, S.E. $=0.05$, Wald $=0.13 \mathrm{df}=1, p=0.72)$. The value of the odds ratio for BI $(\operatorname{Exp}(B)=1.34 ; 95 \%$ CI $[1.15,1.56])$ indicated that for one unit increase in $B I$ (work expectations) the odds of future work participation increase by $34 \%$.

\subsection{Stage 3: Examination and analysis the TPB questionnaire scores}

Having determined that a psychometrically sound model of the expectation of future work participation had been developed, the final analyses aimed to identify the key determinants of those expectations. First, comparisons were made between the 'at work' and 'off work/sickness absent' outcome groups' scores on the direct measures of the TPB predictive components ( $A$, $S N, P B C$ and $B I$ ). As shown in Table 5, the groups were found to be significantly different on all measures and the magnitude of all differences was large.

Both groups had a positive expectation of future work participation (as indicated by the positive $B I$ score), but the 'at work' group's score was significantly higher. Likewise, both groups had an overall positive attitude (A) towards work, but the 'at work' group's score was, again, significantly higher. In contrast, the influence of social pressure $(S N)$, and level of perceived control $(P B C)$, was positive for the 'at work' group, but negative for the 'off work/sickness absent' group. Combining these findings, the expectations associated with being 'at work' in the future were linked with positive influences from all components of the TPB, but the expectations associated with being 'off work/sickness absent' were linked with negative social pressure and barriers to working which, together, outweighed a general positive attitude towards work.

The second step in the analysis involved identifying the most strongly endorsed belief-based items underlying $A, S N$ and $P B C$. From each component, the two items with the highest means were identified (see Table 5). For $A$, and for both groups, these items were from the 'Advantages of working' component, and were 'Feel useful and productive' and 'Increase my social contact'. For $S N$, and for both groups, these items were 'My doctor' and 'Co-workers'. For the 'at work' group the $S N$ total score was positive, but for the 'off work/sickness absent' group it was negative. For $P B C$, the 'at work' group's highest scoring items were a 'Facilitator of working', namely, 'Having duties to go to' and an 'Inhibitor of working' - 'Restricted physical capacity' - but the total $P B C$ score was positive. For the 'off work/sickness absent' group, the highest scores were for 'Inhibitors of working' only - 'Restricted physical capacity' and 'Being in pain' - which led to an overall negative PBC score.

\section{Discussion}

This study developed, validated, and analyzed a TPB model of the factors influencing the future work expectations and outcomes of employees disabled by a musculoskeletal condition. Items generated for the asso- 
Table 5

Direct measure scores on the TPB predictive components and the two underlying beliefs with the highest means scores by RTW outcome group

\begin{tabular}{|c|c|c|c|}
\hline Variable & $\begin{array}{l}\text { At work group } \\
\quad(n=69)\end{array}$ & $\begin{array}{c}\text { Off work/sickness } \\
\text { absent group }(n=62)\end{array}$ & $\begin{array}{l}\text { Significance and magnitude } \\
\text { of difference }\end{array}$ \\
\hline \multicolumn{4}{|c|}{ Behavioral Intention $^{1}$} \\
\hline Mean (SD) & $10.10(2.95)$ & $1.83(7.09)$ & $\begin{array}{c}* * * t(68.27)=-7.62 \\
d=1.52\end{array}$ \\
\hline \multicolumn{4}{|l|}{ Attitude ${ }^{1}$} \\
\hline Mean (SD) & $7.82(5.10)$ & $2.72(7.00)$ & $\begin{array}{c}* * * t(91.14)=-4.12 \\
d=0.83\end{array}$ \\
\hline \multicolumn{4}{|c|}{ Underlying Beliefs: Mean $(\mathrm{SD})^{2}$} \\
\hline & $\begin{array}{l}\text { 1. Feel useful and productive } \\
14.62(8.30)\end{array}$ & $\begin{array}{c}\text { Feel useful and productive } \\
12.78(8.24)\end{array}$ & \\
\hline & $\begin{array}{l}\text { 2. Increase social contact } \\
10.97(9.49)\end{array}$ & $\begin{array}{c}\text { Increase social contact } \\
11.06(8.92)\end{array}$ & \\
\hline \multicolumn{4}{|c|}{ Subjective Norm ${ }^{3}$} \\
\hline Mean (SD) & $3.33(2.67)$ & $-0.41(4.53)$ & $\begin{array}{c}* * * t(82.44)=-5.00 \\
d=1.01\end{array}$ \\
\hline \multicolumn{4}{|c|}{ Underlying beliefs: Mean (SD) ${ }^{2}$} \\
\hline & $\begin{array}{l}\text { 1. Doctor } 7.21 \\
\quad(11.59) \\
\text { 2. Co-workers } \\
-2.82(11.23)\end{array}$ & $\begin{array}{c}\text { Doctor } 4.77 \\
(7.67) \\
\text { Co-workers } \\
-2.52(5.22)\end{array}$ & \\
\hline \multicolumn{4}{|c|}{ Perceived Behavioral Control $^{1}$} \\
\hline Mean (SD) & $6.06(4.83)$ & $-2.21(6.89)$ & $\begin{array}{c}* * * t(89.26)=-6.84 \\
d=1.37\end{array}$ \\
\hline \multicolumn{4}{|c|}{ Underlying Beliefs: Mean $(\mathrm{SD})^{2}$} \\
\hline & $\begin{array}{l}\text { 1. Having duties to go to } \\
8.27 \text { (12.79) } \\
\text { 2. Restricted physical capacity } \\
-6.04(10.47)\end{array}$ & $\begin{array}{c}\text { Restricted physical capacity } \\
-12.81(8.58) \\
\text { Being in pain } \\
-11.16(10.41)\end{array}$ & \\
\hline
\end{tabular}

${ }^{1}$ Possible score range $(-12-+12) ;{ }^{2}$ Possible score range $(-21-+21) ;{ }^{3}$ Possible score range $(-6-+6) ;{ }^{* * *} p<0.001$.

ciated measurement scales included influences on employment that are common to the general population of working adults, but also specific to injured workers. The identified advantages of working included the known benefits of work - financial rewards, time structure, social contact, status, activity and shared goals [35] - but the listed disadvantages reflected limitations particular to musculoskeletal injury: fear of pain and re-injury [36], catastrophizing [37], and emotional distress [38]. The key sources of social pressure to work (or not) were referents that influence adults in general (e.g., family, friends, etc.) and people disabled for work in particular (e.g., treating doctor, employer, and insurer). Similarly, the facilitators of working were found to be the availability of appropriate work or duties and a positive work environment, while the barriers reflected issues to do with symptoms, treatment, and compensation. Overall, the findings suggest that people with injuries want to work for the same reasons - and under the same conditions - as people without injuries, however, barriers to their employment arise from injury-related factors.

The developed TPB model was found to be valid. The model explained $53 \%$ of the variance in work par- ticipation at follow-up - an Odds Ratio representing weak to moderated prediction [39] - which is consistent with the predictive strength of expectations reported in a systematic review of 109 studies of non-specific low back pain [39]. The model also accounted for $76 \%$ of the explained variance in future work expectations $(B I)$ - representing a strong correlation with the predictor variables - and again, demonstrating consistency with the reported predictive relationship between RTW expectations and outcomes [10,11,39-41]. Together, these findings confirmed that the model was sound and suitable for identifying the influences on future work expectation.

The results were examined and analyzed according to outcome group (i.e., 'at work' or 'off work/sickness absent'). Commencing with Behavioral Intention (BI) operationalized as the expectation 'to be working, or continuing to work ... three months from now', the participants who were 'at work' (performing modified duties) had a strong expectation that this would be their ongoing state. Notably, although the future work expectations of those who were 'off work' were low, they were still in the positive range (1.83 on a possible score range of -12 to +12 ) suggesting that de- 
spite being long-term sick listed (on average, around 21 months), these participants nevertheless retained a desire for work resumption.

On examination of the predictors of $B I$, it emerged from the $A$ component that both groups had a positive attitude towards work; the strongest reasons being to 'feel useful and productive' and to have 'social contact'. These findings are consistent with other research demonstrating the importance of the social aspects of work to both the able-bodied [35] and the disabled alike $[42,43]$, and perhaps serve to counter the myth that injured workers 'don't want to work' [44]. From the $S N$ component, it was found that the social pressure underlying the expectation of future work participation was positive for the 'at work' group, but negative for the 'off work' participants. In other words, the combined opinions of significant people were seen as being 'for' work by the first group but 'against' it by the second. Interestingly, for both groups, the key referents were the treating doctor and co-workers; the doctor's opinion carrying the greatest weight. The role of the doctor as gatekeeper to work disability, health-related income support, and work resumption, has been widely documented $[45,46]$. Our results suggest that this opinion also heavily influences the expectation of future work participation. Thus, this finding reinforces the need for ongoing education and support to minimize the likelihood of certifying General Practitioners and Physicians unintentionally creating disability through their communications or actions [45]. The identification of co-workers' opinions as being central to work expectations is also consistent with the known critical role of co-worker support in employee outcomes in general [47] and injured worker outcomes in particular [48-53]. Our findings indicate that both groups perceived co-worker support as being crucial to their RTW success, which underscores the importance of early and ongoing contact [54] and the need to address social aspects of the workplace if RTW expectations and outcomes are to be positive [55].

Finally, the $P B C$ scores and associated underlying beliefs identified differences in the groups' 'ease or difficulty of engaging in the behavior' (i.e., work). For the 'at work' group, perceived control over future work participation was positive: the key underlying belief of 'having duties to go to' (i.e., modified work) off-set the limitations of having 'restricted physical capacity'. In contrast, the negative PBC score of the 'off work' group was the result of high scores on 'restricted physical capacity' and 'pain'. The finding suggests that to increase the RTW expectations of this latter group, management of pain and disability $[8,56,57]$, and the provision of modified work, would be required.

Some limitations of this study should be considered: the most notable is sample size. While the size of the total and sub-samples was comparable to those used in other TPB studies [58], and sufficient to perform the analyses undertaken, caution must be exercised if generalizing the findings to the wider population of interest. This is particularly so given that the response rate was only $35 \%$. Again, while this rate is similar to the average for academic studies in general $-48.4 \%$ $(S D=20.1)$ [59] - and studies of worker compensation recipients in particular $-26.9 \%$ to $60.1 \%$ [60] - care should be exercised when making broader applications.

Another limitation of this study is the very small change, from commencement to follow-up, in participants' work status. At commencement, $51.9 \%$ of the sample was performing some work duties, and at three months follow-up $52.7 \%$ were performing such duties (a non-significant change). Thus, our predicted outcomes were essentially the maintenance of participants' work status at commencement. Although this can be viewed as a positive result, given that people disabled for work by musculoskeletal pain regularly move in and out of the workforce [28-30], the lack of significant change - which is most likely a function of the relatively short follow-up period and the level of chronic disability in the sample - means that the utility of our TPB model to predict RTW outcomes needs to be confirmed in a larger sample, studied over a longer period of time, and involving more participants who are off work/sickness absent at Time 1. That said; the validity of the predictive relationships between expectations $(B I)$ and the underlying TPB constructs - which was the focus of this study - was sound.

\section{Conclusion}

This study has demonstrated that the TPB is a viable theoretical framework for conceptualizing and understanding the factors influencing the future work expectations and outcomes of injured employees. The results suggest a range of biopsychosocial issues combine to produce expectations, and while these vary in importance according to employment status (i.e., off work/sickness absent or at work performing modified duties) the strongest influences are: the availability of modified duties, social aspects of work, communication from the treating doctor, co-worker support and pain-related disability. 


\section{Acknowledgements}

The authors acknowledge with appreciation the following persons and organizations who assisted in the recruitment of participants: WorkCover, NSW; North West Health Consultants; Ada Maughan and Associates; Advanced Personnel Management; Proactive Physiotherapy; Rehab-One; Take Control Active Rehab; Mr. Michael Buckler (Physiotherapist); Dr. Gordon Dandy (Neurosurgeon); Dr. Graeme Edwards (Occupational Physician); and, Barton Lane Practice.

\section{References}

[1] Australian Safety and Compensation Council. Work-related musculoskeletal disease in Australia; 2006 [cited 2010 Dec 12]. Available from: http://www.safeworkaustralia.gov.au/NR /rdonlyres/4DE23D23-D4BF-436E-820E-6DF62B55A7DE/ 0/NOHSCMSDFINALDRAFTwebversion.pdf.

[2] Australian Safety and Compensation Council. The cost of work-related injury and illness for Australian employers, workers and the community: 2005-06; 2009 [cited 2010 Dec 12]. Available from: http://www.safeworkaustralia.gov.au/NR /rdonlyres/EAD5247E-98E7-4750-A35E-A6BC9B1E7781/ 0/CostsofWorkRelatedInjuryAndDisease_Mar2009.pdf.

[3] World Health Organization. The burden of musculoskeletal conditions at the start of the new millennium. In WHO Technical Report Series. Geneva, Switzerland: WHO, 2003.

[4] Medical News Today. Number of work-related accidents and illnesses continues to increase Worldwide. Philadelphia, PA: Lippincott Williams and Wilkins; 2005. [cited 2010 Dec 12]. Available from: http://www.medicalnewstoday.com/articles/ 23543.php.

[5] HSE. Health and Safety Statistics: Self-reported work-related illness and workplace injuries in 2009/10. Suffolk, UK: Health and Safety Executive, 2010. Available from: http://www.hse. gov.uk/statistics/swi/index.htm.

[6] Krause N, Frank JW, Dasinger LK, Sullivan TJ, Sinclair SJ. Determinants of duration of disability and return-to-work after work-related injury and illness: challenges for future research. Am J Ind Med. 2001; 40: 464-484.

[7] Dekkers-Sanchez PM, Wind H, Sluiter JK, Frings-Dresen MHW. A qualitative study of perpetuating factors for longterm sick leave and promoting factors for return to work: Chronic work disabled patients in their own words. J Rehabil Med. 2010; 42(6): 544-552.

[8] Franche R-L, Krause N. Readiness to return to work following injury or illness: conceptualizing the interpersonal impact of health care, workplace, and insurance factors. J OccupRehabil. 2002; 12(4): 233-256.

[9] Kuijer W, Groothoff JW, Brouwer S, Geertzen JHB, Dijkstra PU. Prediction of sickness absence in patients with chronic low back pain: A systematic review. J OccupRehabil. 2006; 16(3): 439-467.

[10] Schultz IZ, Crook J, Meloche GR, Berkowitz J, Milner R, Zuberbier OA, et al. Psychosocial factors predictive of occupational low back disability: towards development of a returnto-work model. Pain. 2004; 107(1-2): 77-85.
[11] Fadyl J, McPherson K. Return to work after injury: A review of evidence regarding expectations and injury perceptions, and their Influence on outcome. J OccupRehabil. 2008; 18(4): 362-374.

[12] Cole DC, Mondloch MV, Hogg-Johnson S. Listening to injured workers: how recovery expectations predict outcomes a prospective study. Can Med Assoc J. 2002; 166(6): 749-754.

[13] Mondloch MV, Cole DC, Frank JW. Does how you do depend on how you think you'll do? A systematic review of the evidence for a relation between patients' recovery expectations and health outcomes. Can Med Assoc J. 2001; 165(2): 174179.

[14] Ajzen I. The theory of planned behavior. Organizational Behavior and Human Decision Processes. 1991; 50: 179-211.

[15] Armitage CJ, Conner M. Social cognition models and health behavior: A structured review. Psychology and Health. 2000; 15: 173-189.

[16] Brouwer S, Krol B, Reneman MF, Bultmann U, Franche RL, van der Klink JJL, et al. Behavioral determinants as predictors of return to work after long-term sickness absence: an application of the Theory of Planned Behavior. J OccupRehabil. 2009;19(2):166-174.

[17] MacEachen E, Clarke J, Franche R-L, Irvin E. Systematic review of the qualitative literature on return to work after injury. Scand. J. Work Environ. 2006;. 32(4): 257-269.

[18] Pincus T, Burton AK, Vogel S, Field AP. A systematic review of psychological factors as predictors of chronicity/disability in prospective cohorts of low back pain. Spine, 2002; 27(5): E109-E120.

[19] Krause N, Dasinger K, Neuhauser F. Modified work and return to work: A review of the literature. J OccupRehabil. 1998; 8(2): 113-139.

[20] Crook J, et al., Determinants of occupational disability following a low back injury: A critical review of the literature. J OccupRehabil. 2002; 12(4): 227-295.

[21] Ajzen I. Constructing a TpB questionnaire: conceptual and methodological considerations. 2002 (updated 2006). [cited 2010 Dec 01]. Available from: www-unix.oit.umass.edu/ aizen/pdf/tpb.measurement.pdf.

[22] Sullivan MJL, Feuerstein M, Gatchel R, Linton SJ, Pransky G. Integrating psychosocial and behavioral interventions to achieve optimal rehabilitation outcomes. J OccupRehabil. 2005; 15(4): 475-489.

[23] de Wit J, Stroebe W. Social cognition models of health behaviour. In: Kaplein A, Weinman J, editors Health Psychology. Oxford, UK: Blackwell Publishing; 2004, pp. 52-82.

[24] Conner M, Sparks P. The theory of planned behavior and health behaviors. In: Conner M, Norman P, editors. Predicting health behavior: research and practice with social cognition models. Buckingham: Open University Press; 1996, pp. 121-162.

[25] Hankins M, French D, Horne R. Statistical guidelines for studies of the theory of reasoned action and the theory of planned behavior. Psychol Health. 2000; 15: 151-161.

[26] Ajzen I, Fishbein M, eds, Understanding attitudes and predicting social behavior. Englewood Cliffs, NJ: Prentice-Hall, 1980.

[27] Trafimow D, Trafimow JH. Predicting back pain sufferers' intentions to exercise. J Psychol. 1998; 132(6): 581-592.

[28] Richardson IH, Richardson PH, Williams AC, Featherstone J, Harding VR. The effects of a cognitive-behavioural pain management programme on the quality of work and employment status of severely impaired chronic pain patients. Disabil Rehabil. 1994; 16(1): 26-34. 
[29] Fishbain DA, Rosomoff HL, Goldbery M, Cutler R, Elsayed A-M, Tarek MK, et al. The prediction of return to the workplace after multidisciplinary pain center treatment. Clin J Pain. 1993; 9: 3-156.

[30] Hansson TH, Hansson EK. The effects of common medical interventions in pain, back function, and work resumption in patients with chronic low back pain: a prospective 2-year cohort study in six countries. Spine, 2000; 25(23): 3055-3064.

[31] Conner M, Norman P. The role of social cognition in health behaviors. In: Conner M, Norman P, editors. Predicting health behavior: research and practice with social cognition models. Buckingham: Open University Press, 1996, 1-22.

[32] WorkCover New South Wales. Statistical Bulletin 2008/2009, Gosford, NSW: Knowledge Management WorkCover Authority of NSW, 2010.

[33] Tabachnick BG, Fidell LS, editors. Using multivariate statistics. 4th ed. Boston: Allyn and Bacon, 2001.

[34] Cohen J, editor. Statistical power analysis for the behavioral sciences: Revised edition. Sydney: Academic Press, 1977.

[35] Jahoda M. Employment and unemployment: A socio-psychological analysis. Cambridge: Cambridge University Press, 1982.

[36] Vlaeyen JWS, Linton SJ. Fear-avoidance and its consequences in chronic musculoskeletal pain: a state of the art. Pain. 2000, 85: 317-332.

[37] Sullivan MJL, Stanish W, Waite H, Sullivan M, Tripp DA. Catastrophizing, pain, and disability in patients with softtissue injuries. Pain. 1998; 77: 253-260.

[38] Linton SJ. A review of psychological risk factors in back and neck pain. Spine. 2000;25(9):1148-1156.

[39] Iles RA, Davidson M, Taylor NF, O'Halloran P. Systematic review of the ability of recovery expectations to predict outcomes in non-chronic non-specific low back pain. J OccupRehabil. 2009; 19(1): 25-40.

[40] Adams JH, Williams ACdeC. What affects return to work for graduates of a pain management program with chronic upper limb pain? J OccupRehabil. 2003; 13(2): 91-106.

[41] Ozegovic D, Carroll LJ, Cassidy DJ. Does expecting mean achieving? The association between expecting to return to work and recovery in whiplash associated disorders: A population-based prospective cohort study. Eur Spine J. 2009; 18(6): 893-899.

[42] Vasconcelos FD. Workers with disability and process for their inclusion in the labor market in Salvador, Bahia, Brazil. Revistabrasileira de saiudeocupacional. 2010; 35(121): 41-52.

[43] Audhoe SS, Hoving JL, Sluiter JK, Frings-Dresen MHW. Vocational interventions for unemployed: Effects on work participation and mental distress. A systematic review. J OccupRehabil. 2010; 20(1): 1-13.

[44] WorkCover Tasmania, Injury Management: Making it Work. 2010. http://www.workcover.tas.gov.au/__data/assets/pdf_file/ 0003/163686/Making_it_Work.pdf.

[45] Dunstan, DA. Are sickness certificates doing our patients harm? AustFam Physic. 2009; 38(1-2): 61-63.

[46] Aylward, M. Fitness for work: Challenging the path to economic inactivity. Abergavenny: Cardiff University, 2007.

[47] Chiaburu DS, Harrison DA. Do peers make the place? Conceptual synthesis and meta-analysis of coworker effects on perceptions, attitudes, OCBs, and performance. Journal of Applied Psychology. 2008; 93(5): 1082-1103.

[48] Post M, Krol B, Groothoff JW. Work-related determinants of return to work of employees on long-term sickness absence.Disabil Rehabil. 2005; 27(9): 481-488.

[49] Glozier N, Hough C, Henderson M, Holland-Elliott K. Attitudes of nursing staff towards co-workers returning from psychiatric and physical illnesses. Int J Soc Psychiatry. 2006; 52(6): 525-534.

[50] Macaden AS, Chandler BJ, Chandler C, Berry A. Sustaining employment after vocational rehabilitation in acquired brain injury. Disabil Rehabil. 2010; 32(14): 1140-1147.

[51] Brouwer S, Reneman MF, Bultmann, U, van der Klink JJL, Groothoff JW. A prospective study of return to work across health conditions: perceived work attitude, self-efficacy and perceived social support. J OccupRehabil. 2010; 20(1): 104112.

[52] Tjulin ÅE, MacEachen E, Ekberg K. Exploring Workplace Actors Experiences of the Social Organization of Return-toWork. J OccupRehabil. 2010; 20(3):311-321.

[53] Tjulin Å, MacEachen E, EdvardssonStiwne E, Ekberg K. The social interaction of return to work explored from co-workers experiences. Disabil Rehabil. 2011; 33(21-22): 1979-1989.

[54] WorkCover NSW. Guidelines for workplace return to work programs. WorkCover Publications: Gosford, Australia, 2010.

[55] MacEachen E, Kosny A, Ferrier S, Chambers L. The "Toxic Dose" of System Problems: Why Some Injured Workers Don't Return to Work as Expected. J OccupRehabil. 2010; 20(3): 349-366.

[56] Rollnick S, Heather N, Bell A. Negotiating behavior change in medical settings: The development of brief motivational interviewing. J Mental Health. 1992; 1: 25-37.

[57] Li EJQ, Li-Tsang CWP, Lam CS, Hui KYL, Chan CCH. The effect of a "training on work readiness" program for workers with musculoskeletal injuries: A randomized control trial (RCT) study. J OccupRehabil. 2006; 16(4): 529-541.

[58] Hardeman W, Johnston M, Johnston DW, Bonetti D, Wareham NJ, Kinmonth AL. Application of the Theory of Planned Behaviour in Behaviour Change Interventions: A Systematic Review. Psychol and Health. 2002; 17(2): 123-158.

[59] Baruch Y. Response rate in academic studies: A comparative analysis. Hum Relat. 1999; 52(4): 421-438.

[60] Centers for Disease Control and Prevention. MMWR Weekly Report. Proportion of workers who were work-injured and payment by worker's compensation systems - 10 states, 2007. July 30, 2010; 59(29). Available from: http://www.cdc.gov/ mmwr/pdf/wk/mm5929.pdf. 